\title{
VITAMIN D STATUS OF ADULTS IN THE OUTPATIENT DEPARTMENT IN BANGLADESH
}

\author{
CHOWDHURY NA ${ }^{1}$, HOSSAIN MZ ${ }^{2}$, MIA MM ${ }^{3}$, HOQUE $\mathrm{S}^{4}, \mathrm{CHOWDHURY} \mathrm{NA}^{5}$, SULTANA R ${ }^{6}$, \\ NIZHU LN ${ }^{7}$
}

\begin{abstract}
Background: Vitamin D deficiency (VDD) is widespread, yet it is the most underdiagnosed and undertreated nutritional deficiency in the world. The prevalence of VDD is estimated to affect over 1 billion people worldwide. The present study was conducted to estimate the prevalence of VDD among adults aged 18-89 years visiting the outpatient department in a clinic/chamber.

Objective: To assess the status of vitamin D deficiency (VDD) among the adult population in Bangladesh.

Methods: A cross sectional study was conducted among 189 adults in the year 2017 including both males and females aged 18-89 years in outpatient department of a clinic/chamber. Venous blood sample was collected for the measurement of Vitamin D (25 hydroxyvitamin D).

Results: This study included a total of 189 adults (29 males and 160 females) aged between 18 and 89 years. Majority of the patients were vitamin D deficient, $67.2 \%$ and $20.6 \%$ were suffering from vitamin $D$ insufficiency. Maximum males and females are deficient, 69\% and 66.9\% respectively where as a very small percentage has sufficient level of vitamin $D$.

Conclusions: Vitamin D deficiency (VDD) is alarmingly high. Screening services should be implemented while researchers focus on strategies to lessen the incidence and morbidity associated with these conditions.
\end{abstract}

Keywords: Vitamin D; Deficiency; Adult; Micronutrient; Bangladesh; VDD.

J Dhaka Med Coll. 2018; 27(1) : 94-97

\section{Introduction}

Vitamin D is known as "The Sunshine Vitamin". The major source of vitamin D for most human is exposure to sunlight. With exposure to ultraviolet (UV) radiation, vitamin D3 is synthesized in human skin via the photo isomerization of 7-dehydrocholesterol (7DHC) which ultimately produces pre-vitamin D3. ${ }^{1}$ Exposure to the amount of sunlight that causes a slight pinkness of the skin after 24 hours $(1 \mathrm{MED})$ is equivalent to ingesting approximately 20,000 IU of vitamin D. ${ }^{2}$ Very few foods naturally contain vitamin D such as Salmon, Sardine, Tuna, Mackerel, Shiitake mushroom, hardboiled egg and foods that are fortified with vitamin D like milk, cereal, orange juice, yogurt, and margarine. But those are inadequate to satisfy the requirement of vitamin $\mathrm{D}$ among children and adult. ${ }^{3}$ Vitamin D deficiency causes rickets among children and osteomalacia in adults, although these represents only the tip of the vitamin D deficiency iceberg. The vitamin $\mathrm{D}$ receptor is distributed in the osteoblasts, small intestine, colon, activated $\mathrm{T}$ and B lymphocytes, B islet cells, mononuclear cells and most other organs in the human body including the brain, heart, skin, gonads, prostate, and breast. ${ }^{4}$ In recent years, there has been lots of study regarding the influence of vitamin $\mathrm{D}$ on extra skeletal health, besides skeletal health. Hypovitaminosis D may be associated with diabetes mellitus ${ }^{5,6}$, cancers ${ }^{7}$, autoimmune diseases ${ }^{8}$, infectious diseases ${ }^{10}$, multiple sclerosis ${ }^{11}$ and other cardiovascular diseases. ${ }^{12}$

Nowadays, vitamin D deficiency is a silent and neglected global public health issue. Almost one billion people in the world suffer from vitamin D deficiency or insufficiency. ${ }^{13}$ There is a

1. Dr. Chowdhury NA, Professor and Head of Department, Department of Medicine, International Medical College, Gazipur

2. Mohammad Zaid Hossain, Associate Professor, Department of Medicine, Dhaka Medical College, Dhaka

3. Mia MM, Resident Physician, Department of Medicine, International Medical College Hospital, Gazipur

4. Hoque S, Medical Officer, Department of Medicine, International Medical College Hospital, Gazipur

5. Chowdhury NA, Medical Officer, Department of Oncology, Delta Medical College Hospital, Dhaka

6. Dr. Rozina Sultana, Registrar, Critical Care Medicine, BIRDEM, Dhaka

7. Dr. Lutfun Nahar Nizhu, Specialist ICU, Square Hospital Ltd. Panthapath, Dhaka 
misconception that vitamin $\mathrm{D}$ deficiency is prevalent only in western countries, but in practical field it is totally reverse. Previously, it was assumed that hypovitaminosis D is less frequent in tropical countries, as cutaneous vitamin $\mathrm{D}$ synthesis is stimulated by exposure to sun. But, surprisingly $80 \%$ of the apparently healthy population is deficient in vitamin $\mathrm{D}(<20$ $\mathrm{ng} / \mathrm{mL}$ ) and up to $40 \%$ of the population is severely deficient $(<10 \mathrm{ng} / \mathrm{mL})$ in South Asia. ${ }^{14}$ Rickets is still widespread in regions, in northern China where $42 \%$ of infants were found to suffer from rickets which occurs as a consequence of vitamin D deficiency during winter and spring season. ${ }^{15}$ According to Siddiqui and Rai in Northern Pakistan, despite of abundant sunlight, rickets was a common problem in infants and children due to malnutrition, lack of awareness and antenatal factors. ${ }^{16}$ High prevalence of vitamin D deficiency in South Asia can be explained by skin pigmentation and traditional clothing. Moreover, air pollution and limited outdoor activity is also responsible for this in the urban population. ${ }^{17}$ In Japan, the status of vitamin D is relatively better than other regions of South Asia due to high sea fish consumption. ${ }^{18}$

Although there is no definite cut off point for the optimal levels of 25-hydroxyvitamin D as measured in serum. According to most expert opinion, vitamin $\mathrm{D}$ deficiency is defined as a 25-hydroxyvitamin D level of less than $50 \mathrm{nmol}$ per liter ${ }^{19}$, which is equivalent to $20 \mathrm{ng} / \mathrm{ml}$. In children, due to fewer outcome data, the optimal level of serum 25(OH)D for general health is not known yet. Moreover, it is controversial than in adults. ${ }^{20,21}$ It is evident that biochemical squeal of vitamin D deficiency may appear at cutoff levels of $75 \mathrm{nmol} / \mathrm{L} .^{22,23}$ Expert opinion suggested that the minimal optimal circulating vitamin D level should be increased from 50 $\mathrm{nmol} / \mathrm{L}$ to $75 \mathrm{nmol} / \mathrm{L} .{ }^{24,25}$ The level of 25hydroxyvitamin D between $50 \mathrm{nmol} / \mathrm{L}$ and 75 $\mathrm{nmol} / \mathrm{L}$ can be considered as a relative insufficiency of vitamin $\mathrm{D}$.

As per above mentioned definitions, the prevalence of vitamin D insufficiency was higher among American children aged 6-11 years (73\%) compared with children aged 1 - 5 years (63\%); girls $(71 \%)$ compared with boys $(67 \%)$; and non-Hispanic black (92\%) and Hispanic $(80 \%)$ children compared with non-Hispanic white children (59\%). ${ }^{26}$ Several other studies suggest that the prevalence of vitamin $\mathrm{D}$ insufficiency among children is 30\% - 50\% in Australia, Turkey, India, and Lebanon. ${ }^{27,28}$

Considering the report from other Asian countries, it is assumed that Bangladesh is at risk of rickets and other vitamin $\mathrm{D}$ deficiency related health consequences. But there is no study regarding Vitamin D deficiency in infant, preschool, school age, adolescence stages and adult. Therefore, we aimed to determine the prevalence of vitamin D deficiency in adult of Bangladesh.

\section{Methods}

Sample

This was a cross sectional study was carried out among 189 adults (18 years and above) who were residents of Dhaka, Bangladesh and visited the clinic/chamber in the year 2017.

\section{Sampling strategy}

Participants were selected through a convenience sampling procedure. All adults aged between 18 to 89 years from every household were included in this study.

\section{Covariates}

We considered the following demographic and life-style variables: age $(\leq 20,21-40,41-60$, $\geq 61$ years) and sex (Male, Female).

We categorized deficient as $<20 \mathrm{ng} / \mathrm{mL}$, insufficient as $20-29 \mathrm{ng} / \mathrm{mL}$ and sufficient as $30-100 \mathrm{ng} / \mathrm{mL}$.

\section{Statistical analysis}

Data were presented as proportions in percentage for categorical variables and mean \pm standard deviation (SD) for continuous variables.

\section{Results}

This study included a total of 189 adults (29 males and 160 females) aged between 18 and 89 years. Majority of the patients were females (84.7\%). More than half, $67.2 \%$ of the patients were vitamin D deficient and $20.6 \%$ were suffering from vitamin $\mathrm{D}$ insufficiency. The socio-demographic characteristics of the patients are given below [see Table-I]. 
Table 1

Socio-demographic characteristics of the patients $(n=189)$

\begin{tabular}{lccc}
\hline Variables & Category & $\begin{array}{c}\text { Number } \\
(\mathrm{n})\end{array}$ & $\begin{array}{c}\text { Percentage } \\
(\%)\end{array}$ \\
\hline Gender & Male & 29 & 15.3 \\
& Female & 160 & 84.7 \\
Age & $\leq 20$ & 6 & 3.2 \\
& $21-40$ & 66 & 34.9 \\
& $41-60$ & 76 & 40.2 \\
& $\geq 61$ & 41 & 21.7 \\
\hline
\end{tabular}

The percentage of deficient, insufficient and sufficient levels of vitamin D within different age group are given in the table below [see Table 2]. The maximum vitamin $D$ deficiency is within the age group $21-40$ years old.

\section{Table-II}

Comparison between age distribution and vitamin $D$ deficiency

\begin{tabular}{lccc}
\hline $\begin{array}{c}\text { Age Group } \\
\text { (years) }\end{array}$ & $\begin{array}{c}\text { Deficient } \\
(\%)\end{array}$ & $\begin{array}{c}\text { Insufficient } \\
(\%)\end{array}$ & $\begin{array}{c}\text { Sufficient } \\
(\%)\end{array}$ \\
\hline$\leq 20$ & $4(66.6)$ & $1(16.7)$ & $1(16.7)$ \\
$21-40$ & $50(75.8)$ & $14(21.2)$ & $2(3.0)$ \\
$41-60$ & $48(63.1)$ & $16(21.1)$ & $12(15.8)$ \\
$\geq 61$ & $25(61.0)$ & $8(19.5)$ & $8(19.5)$ \\
\hline
\end{tabular}

Maximum males and females are deficient, 69\% and $66.9 \%$ respectively where as a very small percentage has sufficient level of vitamin $\mathrm{D}$ [see Table-III].

Table-III

Vitamin D status among male and female

\begin{tabular}{lccc}
\hline Sex & $\begin{array}{c}\text { Deficient } \\
(\%)\end{array}$ & $\begin{array}{c}\text { Insufficient } \\
(\%)\end{array}$ & $\begin{array}{c}\text { Sufficient } \\
(\%)\end{array}$ \\
\hline Male & $20(69.0)$ & $4(13.8)$ & $5(17.2)$ \\
Female & $107(66.9)$ & $35(21.9)$ & $18(11.2)$ \\
Total & $127(67.2)$ & $39(20.6)$ & $23(12.2)$ \\
\hline
\end{tabular}

\section{Discussion}

In this, the first, study of status of vitamin D deficiency (VDD) among the adult population in Bangladesh, we saw the level of Vitamin D (25 hydroxyvitamin D).
The findings suggests that more than half, $67.2 \%$ of the patients were vitamin $\mathrm{D}$ deficient and $20.6 \%$ were suffering from vitamin D insufficiency. The maximum vitamin $D$ deficiency is within the age group $21-40$ years old which is $75.8 \%$ and insufficiency was also within the same group, $21.2 \%$.

Maximum males and females are deficient, 69\% and $66.9 \%$ respectively where as a very small percentage has sufficient level of vitamin D.

The study strengths include large number of sample size. In addition, we maintained the standard of estimating vitamin D level. However, the study has important limitations. We could have taken detailed history about diet, exposure to sun, outdoor activities and correlate it with the vitamin $\mathrm{D}$ level to get a better idea. Therefore, further studies in various settings are needed.

\section{Conclusions}

Our study found very high proportions of vitamin D deficiency (VDD) in Bangladesh and even higher proportion were among the younger group. Screening services should be implemented while researchers focus on strategies to lessen the incidence and morbidity associated with these conditions.

\section{References}

1. Webb, A.R. (2006) Who, What, Where and WhenInfluences on Cutaneous Vitamin D Synthesis. Progress in Biophysics and Molecular Biology, 92, 17-25. https://doi.org/10.1016/j.pbiomolbio. 2006.02.004

2. Holick, M.F. (2010) Vitamin D: Extra Skeletal Health. Endocrinology and Metabolism Clinics of North America, 39, 381-400. https://doi.org/10.1016/ j.ecl.2010.02.016

3. Holick, M.F. and Chen, T.C. (2008) Vitamin D Deficiency: A Worldwide Problem with Health Consequences. The American Journal of Clinical Nutrition, 87, 1080S-1086S.

4. Misra, M., Pacaud, D., Petryk, A., Collett-Solberg, P.F. and Kappy, M. (2008) Vitamin D Deficiency in Children and Its Management: Review of Current Knowledge and Recommendations. Pediatrics, 122, 398-417. https://doi.org/10.1542/peds.2007-1894

5. Pittas, A.G., Lau, J., Hu, F.B. and Dawson-Hughes, B. (2007) The Role of Vitamin D and Calcium in Type 2 Diabetes. A Systematic Review and Meta-Analysis. The Journal of Clinical Endocrinology and 
Metabolism, 92, 2017-2029. https://doi.org/ $10.1210 /$ jc. 2007-0298

6. Svoren, B.M., Volkening, L.K., Wood, J.R. and Laffel, L.M. (2009) Significant Vitamin D Deficiency in Youth with Type 1 Diabetes Mellitus. The Journal of Pediatrics, 154, 132-134. https://doi.org/10.1016/ j.jpeds.2008.07.015

7. Garland, C.F., Gorham, E.D., Mohr, S.B. and Garland, F.C. (2009) Vitamin D for Cancer Prevention: Global Perspective. Annals of Epidemiology, 19, 468483. https://doi.org/10.1016/j.annepidem. 2009.03.021

8. Cutolo, M. and Otsa, K. (2008) Review: Vitamin D, Immunity and Lupus. Lupus, 17, 6-10. https:// doi.org/10.1177/0961203307085879

9. Al Nozha, O.M. (2016) Vitamin D and Extra-Skeletal Health: Causality or Consequence. International Journal of Health Sciences (Qassim), 10, 443-452.

10. Cannell, J.J., Vieth, R., Umhau, J.C., Holick, M.F., Grant, W.B., et al. (2006) Epidemic Influenza and Vitamin D. Epidemiology and Infection, 134, 11291140. https://doi.org/10.1017/S095026880600 7175

11. Munger, K.L., Zhang, S.M., O'Reilly, E., Hernan, M.A., Olek, M.J., et al. (2004) Vitamin D Intake and Incidence of Multiple Sclerosis. Neurology, 62, 6065. https://doi.org/10.1212/01.WNL. 0000101723. 79681.38

12. Wang, T.J., Pencina, M.J., Booth, S.L., Jacques, P.F., Ingelsson, E., et al. (2008) Vitamin D Deficiency and Risk of Cardiovascular Disease. Circulation, 117, 503-511.https://doi.org/10.1161/CIRCULATIONAHA. 107.706127

13. Holick, M.F. (2007) Vitamin D Deficiency. The New England Journal of Medicine, 357, 266-281. https:/ /doi.org/ 10.1056/NEJMra070553

14. Arya, V., Bhambri, R., Godbole, M.M. and Mithal, A. (2004) Vitamin D Status and Its Relationship with Bone Mineral Density in Healthy Asian Indians. Osteoporosis International, 15, 56-61. https:// doi.org/10.1007/s00198-003-1491-3

15. Strand, M.A., Perry, J., Jin, M., Tracer, D.P., Fischer, P.R., Zhang, P., et al. (2007) Diagnosis of Rickets and Reassessment of Prevalence among Rural Children in Northern China. Pediatrics International, 49, 202209. https://doi.org/10.1111/j.1442-200X.2007. 02343. $\mathrm{x}$

16. Siddiqui, T.S. and Rai, M.I. (2005) Presentation and Predisposing Factors of Nutritional Rickets in Children of Hazara Division. Journal of Ayub Medical College, 17, 29-32.

17. Agarwal, K.S., Mughal, M.Z., Upadhyay, P., et al. (2002) The Impact of Atmospheric Pollution on Vitamin D Status of Infants and Toddlers in Delhi
India. Archives of Disease in Childhood, 87, 111-113. https://doi.org/ 10.1136/adc.87.2.111

18. Nakamura, K., Nashimoto, M., Okuda, Y., Ota, T. and Yamamoto, M. (2002) Fish as a Major Source of Vitamin Din the Japanese Diet. Nutrition, 18, 415416.

19. Holick, M.F. (2006) High Prevalence of Vitamin D Inadequacy and Implications for Health. Mayo Clinic Proceedings, 81, 353-373. https://doi.org/10.4065/ 81.3.353

20. Hollis, B.W. (2005) Circulating 25-Hydroxyvitamin D Levels Indicative of Vitamin D Sufficiency: Implications for Establishing a New Effective Dietary Intake Recommendation for Vitamin D. Journal of Nutrition, 135, 317-322.

21. Greer, F.R. (2003) Vitamin D Deficiency-It's More than Rickets. Journal of Pediatrics, 143, 422-423. https://doi.org/10.1067/S0022-3476(03)00465-7

22. Bischoff-Ferrari, H.A., Giovannucci, E., Willett, W.C., Dietrich, T. and Dawson-Hughes, B. (2006) Estimation of Optimal Serum Concentrations of 25Hydroxyvitamin D for Multiple Health Outcomes. The American Journal of Clinical Nutrition, 84, 18-28.

23. Maalouf, J., Nabulsi, M., Vieth, R., Kimball, S., ElRassi, R., Mahfoud, Z. and El-Hajj Fuleihan, G. (2008) Short- and Long-Term Safety of Weekly High-Dose Vitamin D3 Supplementation in School Children. The Journal of Clinical Endocrinology \& Metabolism, 93, 2693-2701. https://doi.org/10.1210/jc.2007-2530

24. Holick, M.F. (2007) Vitamin D Deficiency. The New England Journal of Medicine, 357, 266-281. https:/ /doi.org/ 10.1056/NEJMra070553

25. Yetley, E.A. (2008) Assessing the Vitamin D Status of the US Population. The American Journal of Clinical Nutrition, 88, 558-564. [26] Mansbach, J.M., Ginde, A.A. and Camargo, C.A. (2009) Serum 25Hydroxyvitamin D Levels among US Children Aged 1 to 11 Years: Do Children Need More Vitamin D. Pediatrics , 124, 1404-1410. https://doi.org/ 10.1542/peds.2008-2041

26. [26] Marwaha, R.K., Tandon, N., Reddy, D.R., Aggarwal, R., Singh, R., Sawhney, R.C., Saluja, B., Ganie, M.A. and Singh, S. (2005) Vitamin D and Bone Mineral Density Status of Healthy Schoolchildren in Northern India. The American Journal of Clinical Nutrition, 82, 477-482.

27. El-Hajj, F.G., Nabulsi, M., Choucair, M., Salamoun, M., Hajj Shahine, C., Kizirian, A. and Tannous, R. (2001) Hypovitaminosis D in Healthy Schoolchildren. Pediatrics, 107, 53. https://doi.org/10.1542/ peds.107.4.e53

28. McGrath, J.J., Kimlin, M.G., Saha, S., Eyles, D.W. and Parisi, A.V. (2001) Vitamin D Insufficiency in South-East Queensland. The Medical Journal, 174, 150-151. 